\title{
Marital status, indicators of sexual activity and prostatic cancer
}

\author{
Carlo La Vecchia, Silvia Franceschi, Renato Talamini, Eva Negri, Peter Boyle, Barbara \\ D’Avanzo
}

Istituto di Ricerche Farmacologiche "Mario Negri", Via Eritrea 62, 20157 Milano, Italy. C La Vecchia E Negri

B D'Avanzo

Institute of Social and

Preventive Medicine,

University of

Lausanne, 1005

Lausanne,

Switzerland.

C La Vecchia

Aviano Cancer

Centre, 33081 Aviano

(Pordenone), Italy.

$S$ Franceschi

$\mathrm{R}$ Talamini

Istituto Europeo di

Oncologia, 20122,

Milano, Italy.

P Boyle

Correspondence to: Dr C La Vecchia, Istituto di Recerche Farmacologiche "Mario Negri", Via Eritrea, 62, 20157 Milan, Italy

Accepted for publication June 1993

\begin{abstract}
Study objective-To analyse the relationship between marital status, indicators of sexual activity, history of urological and venereal diseases, and the risk of prostatic cancer. Design-Case-control study.

Setting-A network of cooperating hospitals from northern Italy.

Participants-A total of 271 patients with histologically confirmed prostatic cancer and 685 controls in hospital because of acute, non-neoplastic, non-genital or urological conditions.

Measurements and main results-Relative risks (RR) and the corresponding $95 \%$ confidence intervals (CI) derived from multiple logistic regression equations, including terms for age, area of residence, and education were determined. The risk of prostatic cancer was lower in never married than in married men $(R R=0 \cdot 6)$, but not significantly so. Cases reported a significantly higher number of marriages than control subjects, and the $R R$ was $3 \cdot 2(95 \% C I=1 \cdot 2$, 8.9) for two or more marriages compared with never married men. Prostatic cancer patients also reported being significantly older at the time of their first marriage: compared with men who first married under age 25 years, the $R R$ was 1.6 for marriage at age 25 to 29 , and 1.8 for age 30 or more. With regard to urological or venereal diseases, only cystitis and nephrolitiasis were more frequently reported by cases, although there was no tendency for the risk to increase with the number of cystitis episodes and the RR decreased for longer periods since the first episode.
\end{abstract}

Conclusions-Although these results do not show a totally cohesive picture, they confirm that some aspects of sexual lifestyle are associated with prostatic cancer in Italy.

f Epidemiol Community Health 1993; 47: 450-453

Among common neoplasms, cancer of the prostate is probably the one whose aetiology has been less extensively investigated and is still least clearly understood. Sex hormones are likely to play an important role in the risk of prostatic cancer, since the growth and the development of this organ requires their presence. ${ }^{13}$

Marital status and sexual activity are indicators or indirect measures of hormonal status, and have therefore attracted the interest of epidemiological studies. It has been suggested that the risk of prostatic cancer may be lower in single than in married men ${ }^{4-7}$ and higher in those with more children, ${ }^{8-10}$ but the evidence is not totally consistent. ${ }^{11-14}$

In relation to indicators of sexual activity, prostatic cancer patients have been reported to experience both puberty and first intercourse at a later age than controls, and to have greater sexual drive (as expressed by higher numbers of sexual partners and a more frequent history of venereal or urological diseases. ${ }^{5815}$ For these variables, however, data from other studies have shown conflicting results. ${ }^{15} 16$

To explore these issues further, the relationship between marital status, indicators of sexual habits, a history of urological and venereal disease, and prostatic cancer risk were considered using data from a case-control study conducted in northern Italy.

\section{Subjects and Methods}

The data were derived from a continuing casecontrol study of prostatic cancer which began in January 1985 in the Greater Milan area, northern Italy and the province of Pordenone (north-east Italy). The general design of the study has already been described. ${ }^{17}$ Trained interviewers identified and questioned patients admitted to a network of teaching and general hospitals in the area for prostatic cancer (cases) and a wide spectrum of acute, non-neoplastic, non-genital or urinary tract conditions (controls). The present analysis is based on data collected before December, 1990.

Participation was almost complete, since less than $3 \%$ of cases and controls refused to be interviewed. A structured questionnaire was used to collect sociodemographic factors, personal characteristics and habits; use of tobacco and alcohol in various forms, coffee and other methylxanthine-containing beverages; selected indicator foods, a problem-oriented medical history, a specific drug use history, and history of occupation or occupational exposures. Data were also collected on indirect indicators of sexual habits, such as age at first intercourse, number of sexual partners, age at first marriage, and number of marriages.

\section{CASES}

The cases studied were 271 subjects below the age of 80 (median age 68 years) with histologically confirmed cancer of the prostate diagnosed within the year preceding the interview, who had been admitted to the National Cancer Institute, to several university clinics (chiefly surgical ones), to the Ospedale Maggiore, which includes the four largest teaching and general hospitals in Milan, and to all the hospitals of Pordenone province. 


\section{CONTROLS}

Controls consisted of 685 men below age 79 (median age 61), admitted for acute conditions to the same network of hospitals. Of these, $25 \%$ were admitted for traumas, $26 \%$ for non-traumatic orthopaedic conditions, $19 \%$ for surgical conditions, $17 \%$ for eye diseases, and $13 \%$ for other illnesses, such as skin, ear, nose, throat or dental ailments. Cases and controls were not individually matched by age. A certain imbalance in respect to age derives from the fact that a pool of controls was collected to explore risk factors for more than one neoplasm (that is, bladder, kidney, and prostate) and age distributions do not overlap completely. The catchment area of cases and controls was comparable: overall, $87 \%$ of the cases and $80 \%$ of the controls lived in the same regions (Lombardy and Friuli Venezia Giulia).

DATA ANALYSIS

Since cases were older than controls, odds ratios (OR) of prostatic cancer, together with their $95 \%$

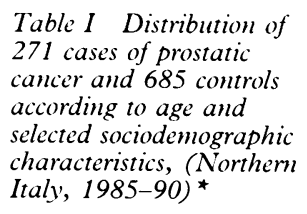

Table II Distribution of 271 cases of prostatic cancer and 685 controls according to marital status and number of children (northern Italy, 1985-90)*

\begin{tabular}{|c|c|c|c|c|}
\hline Characteristics & $\begin{array}{l}\text { Cases } \\
\text { No }\end{array}$ & $\left({ }^{0} o\right)$ & $\begin{array}{l}\text { Controls } \\
\text { No }\end{array}$ & $s(0)$ \\
\hline \multicolumn{5}{|l|}{ Age (v): } \\
\hline$<60$ & 46 & $(17 \cdot 0)$ & 298 & $(43 \cdot 5)$ \\
\hline $60-64$ & 52 & $(19 \cdot 2)$ & 150 & $(21.9)$ \\
\hline $65-69$ & 59 & $(21 \cdot 8)$ & 122 & $(17 \cdot 8)$ \\
\hline $70-74$ & 77 & $(28 \cdot 4)$ & 66 & $(9 \cdot 6)$ \\
\hline $75-79$ & 37 & $(13 \cdot 7)$ & 49 & $(7 \cdot 2)$ \\
\hline \multicolumn{5}{|l|}{ Education (v): } \\
\hline$<6$ & 175 & $(64 \cdot 6)$ & 413 & $(60 \cdot 5)$ \\
\hline $6-8$ & 55 & $(20 \cdot 3)$ & 142 & $(20 \cdot 8)$ \\
\hline$\geq 9$ & 41 & $(15 \cdot 1)$ & 128 & $(18 \cdot 7)$ \\
\hline \multicolumn{5}{|l|}{ Occupation: } \\
\hline Clerical-professional & 87 & $(32 \cdot 3)$ & 233 & $(34 \cdot 5)$ \\
\hline Manual worker & 123 & $(45 \cdot 7)$ & 336 & $(49 \cdot 7)$ \\
\hline Farmer & 53 & $(19 \cdot 7)$ & 90 & $(13 \cdot 3)$ \\
\hline Other or unspecified & 6 & $(2 \cdot 2)$ & 17 & $(2 \cdot 5)$ \\
\hline \multicolumn{5}{|l|}{ Area of residence: } \\
\hline North-eastern Italy & 161 & $(59 \cdot 4)$ & 361 & $(52 \cdot 7)$ \\
\hline Greater Milan area & 110 & $(40 \cdot 6)$ & 324 & $(47 \cdot 3)$ \\
\hline
\end{tabular}

* Some figures do not add up to the total because of missing values.

\begin{tabular}{|c|c|c|c|}
\hline & $\begin{array}{l}\text { Prostatic } \\
\text { cancer }\end{array}$ & Controls & $\begin{array}{l}\text { Odds ratiof } \\
\left(95^{\circ} \% \mathrm{CI}\right)\end{array}$ \\
\hline \multicolumn{4}{|l|}{ Marital status: } \\
\hline & 231 & 571 & \multirow{3}{*}{$\begin{array}{l}1 \neq \\
0 \cdot 7 \\
(0 \cdot 4,1 \cdot 2) \\
0 \cdot 6 \\
(0 \cdot 3,1 \cdot 2)\end{array}$} \\
\hline Widowed, divorced, etc. & 29 & 65 & \\
\hline Never married & 11 & 49 & \\
\hline \multicolumn{4}{|l|}{ Age at first marriage (y): } \\
\hline $\begin{array}{l}<25 \\
25-29\end{array}$ & $\begin{array}{r}41 \\
124\end{array}$ & $\begin{array}{l}161 \\
298\end{array}$ & \multirow{3}{*}{$\begin{array}{l}1 \neq \\
1 \cdot 6 \\
(1 \cdot 1,2 \cdot 5) \\
1 \cdot 8 \\
(1 \cdot 2,2 \cdot 8) \\
5 \cdot 92 \\
(\mathrm{p}=0 \cdot 02)\end{array}$} \\
\hline$\geq 30$ & 94 & 176 & \\
\hline$\chi_{i}^{2}$ (trend) & & & \\
\hline \multicolumn{4}{|l|}{ No of marriages: } \\
\hline 0 & 11 & 49 & \multirow{5}{*}{$\begin{array}{l}1 \neq \\
1 \cdot 6 \\
(0 \cdot 8,3 \cdot 3) \\
3 \cdot 2 \\
(1 \cdot 2,8 \cdot 9) \\
5 \cdot 16 \\
(p=0 \cdot 02)\end{array}$} \\
\hline 1 & 245 & 618 & \\
\hline$\geq 2$ & 15 & 18 & \\
\hline$\chi_{i}^{2}$ (trend) & & & \\
\hline \multicolumn{3}{|l|}{ No of children: } & \\
\hline 0 & 38 & 111 & \multirow{6}{*}{$\begin{array}{l}1 \neq \\
1 \cdot 3 \\
(0 \cdot 7,2 \cdot 1) \\
1 \cdot 0 \\
(0 \cdot 6,1 \cdot 6) \\
1 \cdot 5 \\
(0 \cdot 9,2 \cdot 5) \\
1 \cdot 2 \\
(0 \cdot 7,2 \cdot 0) \\
0 \cdot 58 \\
(\mathrm{p}=0 \cdot 44)\end{array}$} \\
\hline 1 & 50 & 111 & \\
\hline 2 & 76 & 244 & \\
\hline 3 & 59 & 118 & \\
\hline$\geq 4$ & 48 & 99 & \\
\hline$x_{i}^{2}$ (trend) & & & \\
\hline $\begin{array}{l}\text { ^ Some figures do not add } \\
\text { values. } \\
+ \text { Estimates from multiple } \\
\text { including terms for age, ar } \\
\ddagger \text { Reference category. }\end{array}$ & $\begin{array}{l}\text { the to } \\
\text { c regr } \\
\text { esider }\end{array}$ & beca & $\begin{array}{l}\text { e of missing } \\
\text { tions } \\
\text { ucation. }\end{array}$ \\
\hline
\end{tabular}

confidence intervals (CI), were first computed from data stratified by quinquennia of age by the Mantel-Haenszel procedure. ${ }^{18}$ Significance was assessed by the linear trend test described by Mantel. ${ }^{19}$ In addition, to account simultaneously for the potential confounding effect of various factors, multiple logistic regression was used, ${ }^{20} 21$ including terms for age, area of residence (Lombardy, Friuli Venezia Giulia, other), and education. These factors were identified a priori since they may influence marital status, indicators of sexual activity, and urological and venereal diseases. Since the results were similar, only multiple logistic regression estimates were chosen for presentation.

\section{Results}

Table I gives the distribution of cases of prostatic cancer and the comparison group according to age and selected socio-demographic indicators. After allowance for age, no difference was observed between cases and controls according to education and occupation.

Table II considers several aspects of marital status and reproductive experience. Although the risk of prostatic cancer was lower in men who had never married than in married men, the reduction in risk was not significant $(\mathrm{OR}=0 \cdot 6,95 \% \mathrm{CI} 0 \cdot 3$, $1 \cdot 2$ ). Cases reported being significantly older at first marriage than controls: compared with men whose first marriage was before age 25 years, the OR was 1.6 for marriage at age 25 to 29 years, and 1.8 for age 30 or more, and the test for trend in risk was significant. Prostatic cancer cases were more likely to have married more than once than controls: compared with men who had never married, the OR was 1.6 for one and $3 \cdot 2(95 \% \mathrm{CI}$ : $1 \cdot 2,8 \cdot 9)$ for two or more marriages. This trend in risk was also significant. In relation to the number of children, no linear trend in risk was observed, although the OR tended to be non-significantly above unity in men who had had children compared with childless men (OR for $\geq 1$ versus 0 children $=1 \cdot 2,95 \%$ CI: $0 \cdot 8,1 \cdot 8$ ) (table II).

Selected indicators of sexual habits are considered in table III. Cases of prostatic cancer tended to report their first intercourse at an older age than controls $(\mathrm{OR}=1.3$ for $\geq 20 v<18)$, but had had a slightly higher number of sexual partners (OR for $>1 v \leq 1$ sexual partners $=1 \cdot 3,95 \%$ CI: $0.9,1.8)$. None of the trends for these variables, however, was statistically significant (table III). Frequency of sexual intercourse was investigated in three different periods of life (under 25 years, 25 to 44 , and 45 and over). In none of these was any significant difference observed between cases and controls (data not shown).

A history of selected urological and venereal diseases is presented in table IV. Cases reported episodes of cystitis more frequently than controls: the OR was 1.4 for one or two, and 1.8 for three or more episodes. In addition, nephrolitiasis (kidney or bladder stones) seemed to have occurred slightly more frequently in prostatic cancer patients than in control subjects. No significant difference was observed for gonorrhea or in other diseases such as syphilis, herpes genitalis, or condilomata acuminata that are not presented in 
Table III Distribution of 271 cases of prostatic cancer and 685 controls according to indicators of sexual activity (northern Italy, 1985-90)*

Table IV Distribution of 271 cases of prostatic cancer and 685 controls according to history of selected urological and venereal diseases (Milan, Italy, 1985-90)*

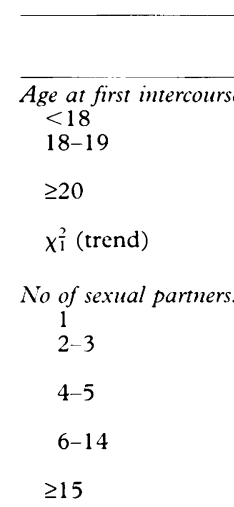

$x_{1}^{2}$ (trend)

Some figures do not add up to the total because of missing values.

t Estimates from multiple logistic regression equations including terms for age, area of residence, and education. $\ddagger$ Reference category.

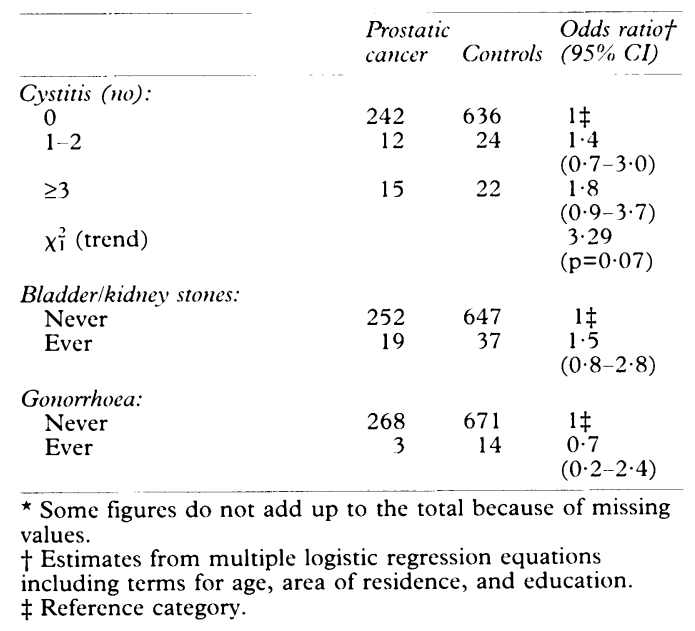

the table because of small absolute numbers of subjects exposed.

\section{Discussion}

This study confirmed that a few correlates of sexual and lifestyle factors are associated with the risk of prostatic cancer. Cases were more likely to have married more than once more than control subjects, and had had slightly more sexual partners, but the first marriage and the age at first intercourse tended to occur at an older age. Although these findings do not present a cohesive picture, they confirm, in general terms, the existence of differences in such indicators between prostatic neoplasia cases and a comparison group of hospital controls not affected by genital or urological disorders.

The differences have usually been interpreted in terms of greater "sexual drive" 351516 in prostatic cancer cases. This could, in fact, be reconciled with the larger number of marriages and of sexual partners found in this study, and, though only indirectly, with the later age at first marriage and the somewhat larger number of children.

It is more difficult to offer any biological interpretation of these findings. Among those most frequently proposed are differences in hormonal levels and, in particular, higher levels of serum testosterone $\mathrm{e}^{22} 23$ or androstenedione $\mathrm{e}^{24}$ in subjects with prostatic cancer, or the implication in prostatic cancer aetiology of sexually transmitted infectious agents. ${ }^{1-3}$

This is, to some extent, supported by the significant association in this study with a history of cystitis, although bladder and urinary tract infections may simply reflect early symptoms of urinary retention because of prostatic enlargement, as suggested by a flattening of the risk with longer time since the first episode of cystitis. The same holds true for the insignificant excess of kidney and bladder stones in prostatic cancer cases. However, a history of several sexually transmitted diseases was reported so infrequently by the present population that no conclusion could be drawn.

History of disease may be affected by recall bias, since cases were probably more sensitised than controls towards recalling urinary tract conditions. This kind of bias is probably reduced by the hospital based design of the study, which has the advantage of favouring conditions for similar recall of medical histories. ${ }^{25}$ Other limitations and strengths of hospital based, case-control studies have been widely discussed. ${ }^{18}{ }^{20}$ It is nonetheless useful to recall at least the fact that, while this study was not population based and had no cancer registration scheme towards which recruitment of cases could be checked, the hospitals under surveillance included most of those in the Greater Milan area and all the hospitals in the province of Pordenone, and the participation rate of identified cases and controls was almost complete. With respect to confounding, the results were not appreciably influenced for allowance for major sociodemographic indicators.

In conclusion, therefore, the inherent limitations in the information collected, the limited statistical power due to the relative small absolute number of cases (at least in respect to risk factors apparently as weak as those examined), the lack of coherence, and the uncertainties in the interpretation of some results do not, in our opinion, entirely eclipse the interest of the observation that prostatic cancer cases differ from a comparison group in relation to a number of indicators of sexual habits.

This work was conducted within the framework of the CNR (Italian National Research Council) applied projects "Clinical applications of oncological research" (Contract no 92.02384.PF39) and "Prevention and control of disease factors" (Contract no 92.00229.PF41), and with the contributions of the Italian Association for Cancer Research, the Italian League Against Tumours, Milan, and Mrs A Marchegiano Borgomainerio. The authors wish to thank Mrs J Baggott, Mrs M P Bonifacino, and G A Pfeiffer Memorial Library staff for editorial assistance.

1 Mandel JS, Schuman LM. Epidemiology of cancer of the prostate. In: Lilienfeld AM, ed. Reviews in cancer prostate. In: Lilienfeld AM, ed. Reviews

epidemiology. New York: Elsevier, 1980. 1 -83. Bosland MC. The etiopathogenesis of prostatic cancer with special reference to environmental factors. Adv Cancer Rc

Boyle P, La Vecchia C, Maisonneuve P, Zheng T, Zaridze Boyle P, La Vecchia C, Maisonneuve P, Zheng T, Zaridze
DG. The epidemiology of prostate cancer. In: Prostate DG. The epidemiology of prostate cancer

cancer. Berlin: Springer Verlag (in press).
4 King $\mathrm{H}$, Diamond E, Lilienfeld AM. Some epidemiological King H, Diamond E, Lilienfeld AM. Some epidemiological
aspects of cancer of the prostate. $f$ Chronic Dis 1963; 16: aspects of cancer of the prostate. F Chromic Dis 1963, 16 : 11753.

5 Steele R, Lees REM, Kraus AS, Rao C. Sexual factors in the epidemiology of cancer of the prostate. 7 Chronic Dis 1971 24: $29-37$.

6 Ross RK, McCurtis JW, Henderson BE, Menck HR, Mack TM, Martin SP. Descriptive epidemiology of testicular and prostatic cancer in Los Angeles. Br $\mathcal{F}$ Ciancer 1979; 39 284-92. 
7 Newell GR, Pollack ES, Spitz MR, Sider JG, Fueger JJ. Incidence of prostate cancer and marital status. $\mathcal{F}$ Natl Cancer Inst 1987; 79: 259-62.

8 Lancaster HO. The mortality in Australia from cancer peculiar to the male. Med f A ust 1952; 2: 41-4.

9 Greenwald P, Damon A, Kirmss V, Polan AK. Physical and demographic features of men before developing cancer of the prostate f lul Cuncer Inst 1974; 53:341-6.

10 Armenian HK, Lilienfeld AM, Diamond EL, Bross IDJ Epidemiologic characteristics of patients with prostatic Epidemiologic characteristics of patients with prostatic

neoplasms. Am Epideniml $1975,102.47-54$.

Wynder EL, Maruchi K, Whitmore WF. Epidemiology of cancer of the prostate. Cancer 1971; 28: 344-60.

12 Ross RK, Deapen DM, Casagrande JT, Paganini-Hill A Henderson BE. A cohort study of mortality from cancer of the prostate in Catholic priests. Brf Cancer 1981; 43: 233-5.

13 Talamini R, La Vecchia C, Decarli A, Negri E, Franceschi S Nutrition, social factors and prostatic cancer in a Northern Italian population. $\operatorname{Br} \mathcal{F}$ Cancer $1986 ; 53: 817-21$.

14 Newell GR, Fueger JJ, Spitz.MR, Babaian RJ. A case-control study of prostate cancer. Am $\mathcal{F}$ Epidemiol $1989 ; 130$ : 395-8

15 Rotkin ID. Studies in the epidemiology of prostatic cancer: Expanded sampling Cancer Treatment Report 1977, 61: $173-80$.

16 Honda GD, Bernstein L, Ross RK, Greenland S, Gerkins V, Henderson BE. Vasectomy, cigarette smoking, and age at first sexual intercourse as risk factors for prostate cancer in middle-aged men. Br f Cancer 1988; 57: 326-31.
17 La Vecchia C, Negri E, D'Avanzo B, Franceschi S, Boyle P. Dairy products and the risk of prostatic cancer. Oncology 1991; 48: 406-10.

18 Mantel $\mathcal{N}$, Haenszel W. Statistical aspects of the analysis of data from retrospective studies of disease. 7 Natl Cancer Inst 1959; 22: 719-48.

19 Mantel N. Chi-square tests with one degree of freedom; extensions of the Mantel-Haenszel procedure. Foumal of the American Statistical Association 1963; 58: 690-700.

20 Breslow. NE, Day NE. Statistical methods in cancer research vol. 1. The analysis of case-control studies. Lyon: IARC Sci Publ, 1980; 82.

21 Baker RJ, Nelder JA. The GLIM system, release 3. Oxford: Numerical Algorithms Group; 1978.

22 Ghanadian R, Puah CM, O'Donoghue EPN. Serum testosterone and dihydrotestosterone in carcinoma of the testosterone and dihydrotestosterone in

23 Ross R, Bernstein L, Judd H, Hanisch R, Pike M, Henderson B. Serum testosterone levels in healthy young black and white men. I Natl Cancer Inst 1986; 76: 45-8.

24 Barrett-Connor E, Garland C, McPhillips JB, Khaw K, Wingard DL. A prospective, population-based study of androstenedione, estrogens, and prostatic cancer. Cancer Res 1990; 50: 169-73.

25 Kelly JP, Rosenberg L, Kaufman DW, Shapiro S. Reliability of personal interview data in a hospital-based case-control study. Am F Epidemiol 1990; 131: 79-90. 